\title{
Pulmonary vein stenosis: Treatment and challenges
}

\author{
Rachel D. Vanderlaan, MD, PhD, ${ }^{\mathrm{a}}$ Jonathan Rome, MD, ${ }^{\mathrm{b}}$ Russel Hirsch, MD, ${ }^{\mathrm{c}}$ Dunbar Ivy, MD, ${ }^{\mathrm{d}}$ and \\ Christopher A. Caldarone, $\mathrm{MD}^{\mathrm{e}, \mathrm{f}}$
}

Pulmonary vein stenosis (PVS) remains a formidable clinical challenge in congenital heart disease. In recent years, the medical community has pushed to advance our understanding and treatment of this disease. Experimental therapies, surveillance modalities, and advancements in surgical and transcatheter interventions are reviewed, with emphasis on the current challenges facing the PVS clinical community.

In contrast to the indolent course of PVS found in adults following radiofrequency ablation, ${ }^{1}$ PVS in children and infants can be relentless and progressive and is characterized by neointimal obstruction of the pulmonary veins leading to secondary pulmonary hypertension and right heart failure (Figure 1). The spectrum of PVS is broad. Single vessel stenosis is well tolerated; however, 2-year survival for infants and children with progressive PVS is approximately $50 \%$ to $60 \%$. Earlier age at diagnosis and multiple vein involvement are hallmarks of poor prognosis. ${ }^{2-4}$ Within the spectrum of pediatric PVS, 2 clinical categories are encountered: primary PVS and postrepair PVS (PR-PVS).

Primary (congenital) PVS occurs in patients with normally connected pulmonary veins without prior surgical interventions, although other congenital heart disease may be present. Markers of poor prognosis include bilateral PVS, involvement of 3 or more pulmonary veins and earlier age at diagnosis. ${ }^{2,4}$ Primary PVS in a premature infant may be a distinct entity and can be associated with lungrelated and other comorbidities that may influence disease trajectory and treatment strategies. ${ }^{6-8}$ PR-PVS includes patients who develop PVS after surgical interventions on the pulmonary veins. After repair of total anomalous pulmonary venous connection (TAPVC), PR-PVS occurs in 5\% to $15 \%$ of patients and 1 -year survival is $55 \%$ to $63 \% .^{9-11}$

\footnotetext{
From the ${ }^{\mathrm{a} D i v i s i o n}$ of Cardiovascular Surgery, Hospital for Sick Children, Toronto, Ontario, Canada; 'Division of Cardiology, Department of Pediatrics, Children's Hospital of Philadelphia, Philadelphia, Pa; ' $D$ Division of Cardiology, Department of Pediatrics, Cincinnati Children's Hospital, Cincinnati, Ohio; ${ }^{\mathrm{d} D i v i s i o n}$ of Cardiology, Department of Pediatrics, Children's Hospital Colorado, Aurora, Colo; and ${ }^{\mathrm{e}}$ Division of Congenital Heart Surgery, Texas Children's Hospital; and ${ }^{\mathrm{f}}$ Michael E. DeBakey Department of Surgery, Baylor College of Medicine, Houston, Tex.

Received for publication March 13, 2020; revisions received May 19, 2020; accepted for publication May 23, 2020; available ahead of print June 27, 2020.

Address for reprints: Rachel D. Vanderlaan, MD, PhD, Division of Cardiovascular Surgery, Hospital for Sick Children, Rm 1525D, Hill Wing, 555 University Ave,

Toronto, Ontario, Canada M5G 1X8 (E-mail: Rachel.vanderlaan@sickkids.ca).

J Thorac Cardiovasc Surg 2021;161:2169-76

$0022-5223 / \$ 36.00$

Copyright (c) 2020 by The American Association for Thoracic Surgery

https://doi.org/10.1016/j.jtcvs.2020.05.117
}

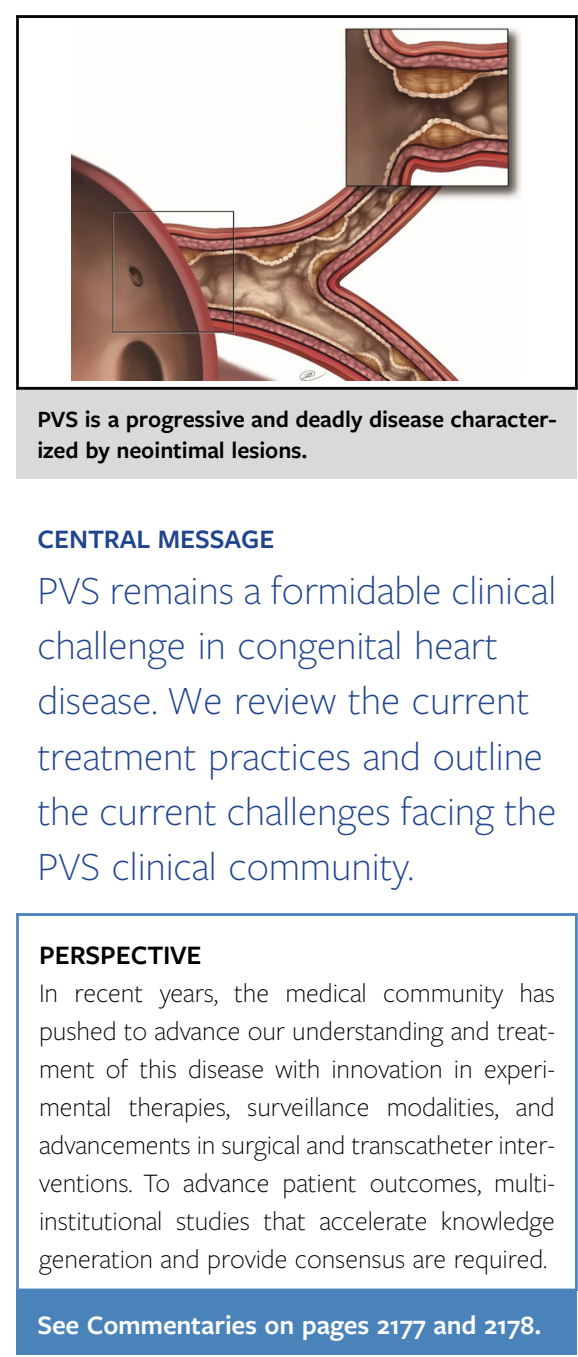

Despite aggressive multimodality approaches with surgical and catheter-based interventions, survival with multivessel primary PVS and PR-PVS remains poor.

\section{ETIOLOGY AND DISEASE MECHANISMS}

The etiology of PVS remains elusive. One genetic locus (no candidate gene) has been associated with primary PVS and abnormal lymphatic development, ${ }^{12}$ whereas associated chromosomal abnormalities and syndromes, such as trisomy 21 and heterotaxy syndrome, are common. ${ }^{2}$ Postulated contributory factors include disrupted pulmonary vein signaling during embryonic development, ${ }^{13,14}$ external compression from thoracic structures (eg, cardiomegaly and anterior displacement of the descending aorta), local 


$$
\begin{aligned}
& \text { Abbreviations and Acronyms } \\
& \text { BA }=\text { balloon angioplasty } \\
& \text { BMS }=\text { bare metal stent } \\
& \text { DES }=\text { drug-eluting stent } \\
& \text { ISS } \text { in-stent stenosis } \\
& \text { PR-PVS }=\text { postrepair PVS } \\
& \text { PVS }=\text { pulmonary vein stenosis } \\
& \text { TAPVC }=\text { total anomalous pulmonary venous } \\
& \text { connection }
\end{aligned}
$$

distortion of veins due to atelectasis, and local injury at the site of TAPVC repair. ${ }^{15}$ Histological analysis of PVS lesions demonstrates focal or diffuse lesions with myofibroblast-like cells and extracellular matrix deposition $^{16,17}$ (Figure 2, A) with activated tyrosine kinase receptors noted in human specimens. ${ }^{18}$ In a surgical porcine model, neointimal lesions were associated with transforming growth factor beta signaling and activation of other signaling pathways. ${ }^{19,20}$ Myofibroblast deposition is a common feature of PVS (Figure 2, $B$ ) and therapies targeting myofibroblast deposition may have a beneficial effect.

\section{DIAGNOSIS AND SURVEILLANCE FOR PVS}

The most common screening modality for PVS is echocardiography, and it is most accurate when evaluating PVS limited to the venoatrial junction and when there is balanced circulation between both lungs. When pulmonary venous flow is shunted away from obstructed pulmonary veins to less obstructed pulmonary veins, systemic veins, or retrograde pulmonary artery flow (ie, intrapulmonary flow redistribution), ${ }^{21}$ the severity of PVS may be underestimated by Doppler gradients alone. Complementary assessments of right ventricle function and pulmonary artery flow patterns provide important physiologic information to integrate with clinical assessment and other diagnostic studies.
Cross-sectional imaging such as computed tomography angiography and magnetic resonance angiography can be used to provide important hemodynamic data, anatomy of the pulmonary veins, and the degree of stenosis at the left atrial junction or upstream in the lung parenchyma. Computed tomography angiography typically does not require sedation, has excellent anatomical rendering with low radiation doses, and can measure upstream pulmonary vein dimensions. ${ }^{22,23}$ Magnetic resonance angiography additionally contributes functional measurements of flow in the pulmonary veins and quantification of flow redistribution. ${ }^{24,25}$ In the setting of severe obstruction and flow redistribution, it can be difficult to appreciate pulmonary vein patency and diameters distal to a stenosis by crosssectional imaging. Lung perfusion scans can quantify perfusion to various lung segments and provides additional complementary information. ${ }^{26}$

Diagnostic catheterization remains the gold standard, providing anatomic detail and important hemodynamic information. Many centers reserve catheterization for children with a high probability of requiring an intervention or for evaluation of pulmonary vasodilator therapy.

\section{TREATMENT OF PVS \\ Catheter-Based Interventions}

Although catheter-based interventions are associated with high rates of restenosis, they play in important role in multimodality management of PVS. Balloon angioplasty (BA) is associated with acute hemodynamic and angiographic evidence of relief of PVS; however, restenosis is the rule with no difference between BA and cutting BA (freedom from reintervention at 1 year of $15 \%$ for cutting BA and $23 \%$ for BA) ${ }^{27}$ Although there have been no direct comparisons between stenting and BA, it appears that endovascular stenting results in better acute gradient relief and larger initial diameter increase. However, restenosis after stent angioplasty is common. Early studies using bare metal stent (BMS) in patients with PVS and congenital heart disease demonstrated freedom from occlusion or severe
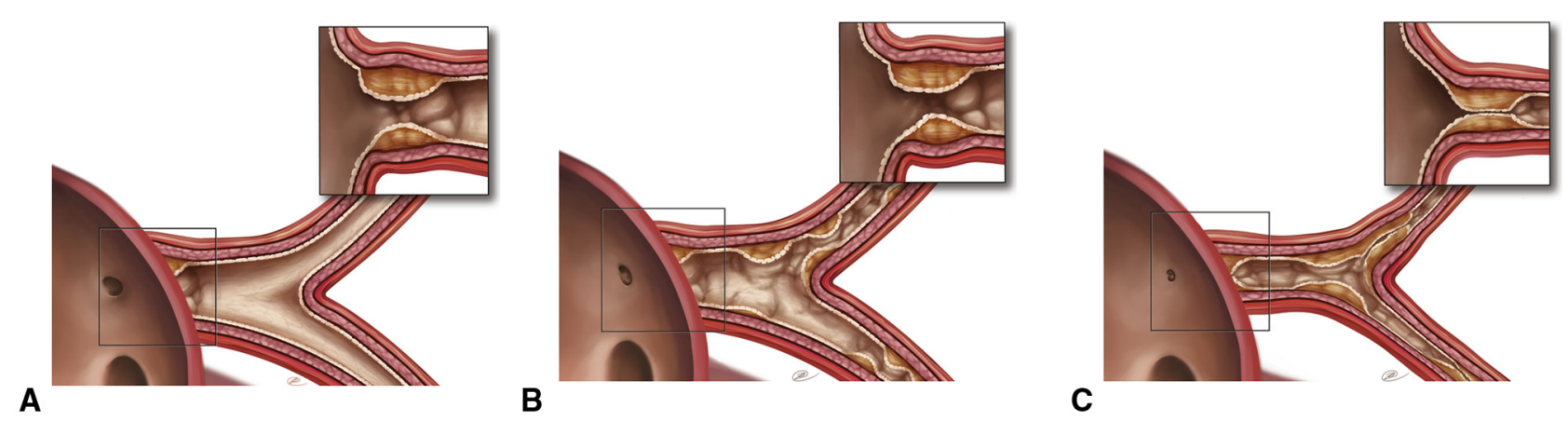

FIGURE 1. Pulmonary vein stenosis (PVS). A, Discrete focal stenosis at the venoatrial junction. B, Progressive PVS that extends into the intraparenchymal or so-called upstream veins. C, Diffuse stenosis leading to atresia of the vein. Reprint permission granted by Rachel Vanderlaan, PVSNetwork.org. 

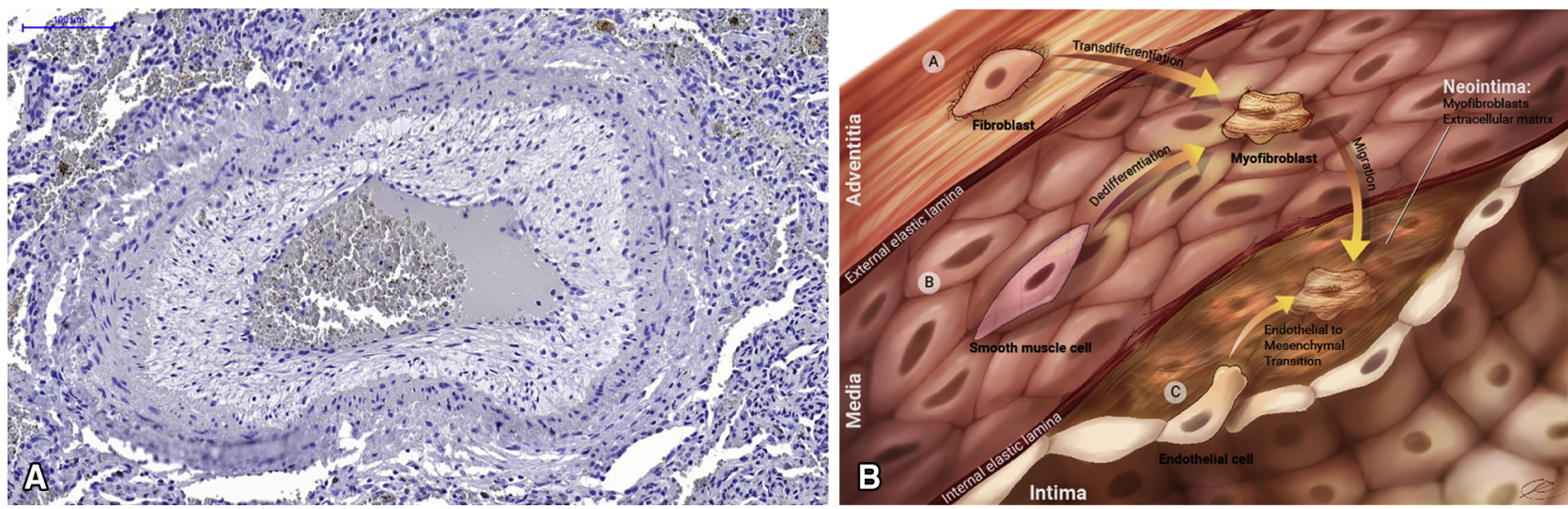

FIGURE 2. Neointima lesions in pulmonary vein stenosis (PVS). A, Histologic section of neointimal lesions in children with PVS. Neointimal lesions demonstrate deposition of myofibroblast-like cells and increased extracellular matrix. B, Potential mechanism of myofibroblast deposition contribution to neointimal formation in children with PVS. Potential sources of myofibroblast cells are (A) fibroblasts from the adventitia. These cells can proliferate in response to different signals and transdifferentiate into myofibroblasts that are capable of migration into the neointima. (B) Smooth muscle cells can be stimulated by different signaling molecules to deifferentiate into myofibroblasts that can migrate into the neointima. (C) Endothelial cells can also undergo a specialized process called endothelial-to-mesenchymal transition. Endothelial cells will loss specific cell markers and take on myofibroblast properties. These cells can then move into the neointima. There are potential other sources of cells, such as circulating progenitors or proliferating pericytes. Reprint permission granted by Rachel Vanderlaan, PVSNetwork.org.

in-stent stenosis (ISS) of $37 \%$ at 1 year. ${ }^{28}$ Stents with a luminal diameter $>7 \mathrm{~mm}$ were associated with a longer freedom to reintervention. ${ }^{28}$

In efforts to mitigate ISS, drug-eluting stents (DESs) for treatment of PVS have been increasingly used. Drug-eluting balloons have also been applied but results are limited to small case reports in PVS patients. ${ }^{29}$ A single-institution study recently demonstrated lower rates of lumen loss in DESs compared with BMSs, ${ }^{30}$ whereas another singlecenter study demonstrated a trend toward increased 1-year survival in patients who received a DES compared with BMS or BA recipients. ${ }^{31}$ It has been noted that DESs and drug-eluting balloons in infants with PVS can result in transient peak serum drug levels similar to systemic therapy. ${ }^{29}$ The maximum diameter DES currently available is $5 \mathrm{~mm}$; thus somatic growth has the potential for mismatch between the stented and growing pulmonary vein (even in the absence of ISS). Intentional stent fracture with highpressure BA has been successfully employed to address this problem. ${ }^{30,32}$ Utilization of systemic adjunct treatment to potentially decrease ISS in high-risk patients has been reported but without formal evaluation. ${ }^{3}$

Bioabsorbable devices are potentially an attractive solution to concerns of somatic growth mismatch with stents. Whereas early-generation devices resulted in substantial neointimal proliferation, current-generation biobsorbable drug-eluting platforms are being evaluated in coronary disease. Bioabsorbable devices have not been evaluated in pulmonary veins. New-generation bioabsorbable stents are showing improved results in the coronary literature and have the potential to crossover into the pediatric PVS armamentarium in the future.

\section{Surgical Repair of PVS}

The sutureless technique evolved in response to the high incidence of PR-PVS after TAPVC repair and involves anastomosis of the left atrium to the pericardium (rather than the pulmonary veins) to minimize intimal injury and pulmonary vein distortion (Figure 3). Single-center reports of superior outcomes with the sutureless technique have led to widespread adoption to treat PR-PVS. ${ }^{11,34,35}$

The sutureless technique has been examined as a prophylactic strategy at the time of TAPVC repair to prevent PR-PVS. ${ }^{36,37}$ A large, retrospective cohort demonstrated a beneficial prophylactic effect in the subset of patients with preoperative pulmonary venous obstruction, ${ }^{10}$ whereas a small series reported diminished PR-PVS with infracardiac and mixed TAPVC. ${ }^{34}$ Extrapolation of the sutureless technique to primary PVS is still associated with poor prognosis in patients with aggressive disease. ${ }^{4}$

Although the sutureless technique appears advantageous for disease localized to the left atrial junction, the technique does not significantly modify pulmonary veins beyond the first order branches. When upstream stenosis is present, smaller intraluminal dimensions of the upstream pulmonary veins are generally associated with poor outcomes after surgical repair (Figure 4, A). Experimental models of PVS suggest upstream propagation may result from downstream obstruction, suggesting that early diagnosis and prompt surgical intervention before upstream disease progression may be an effective strategy.

To modify stenosis outside the pericardial reflection, an approach described involves resection and anastomosis of the posterior walls of adjacent pulmonary veins outside 


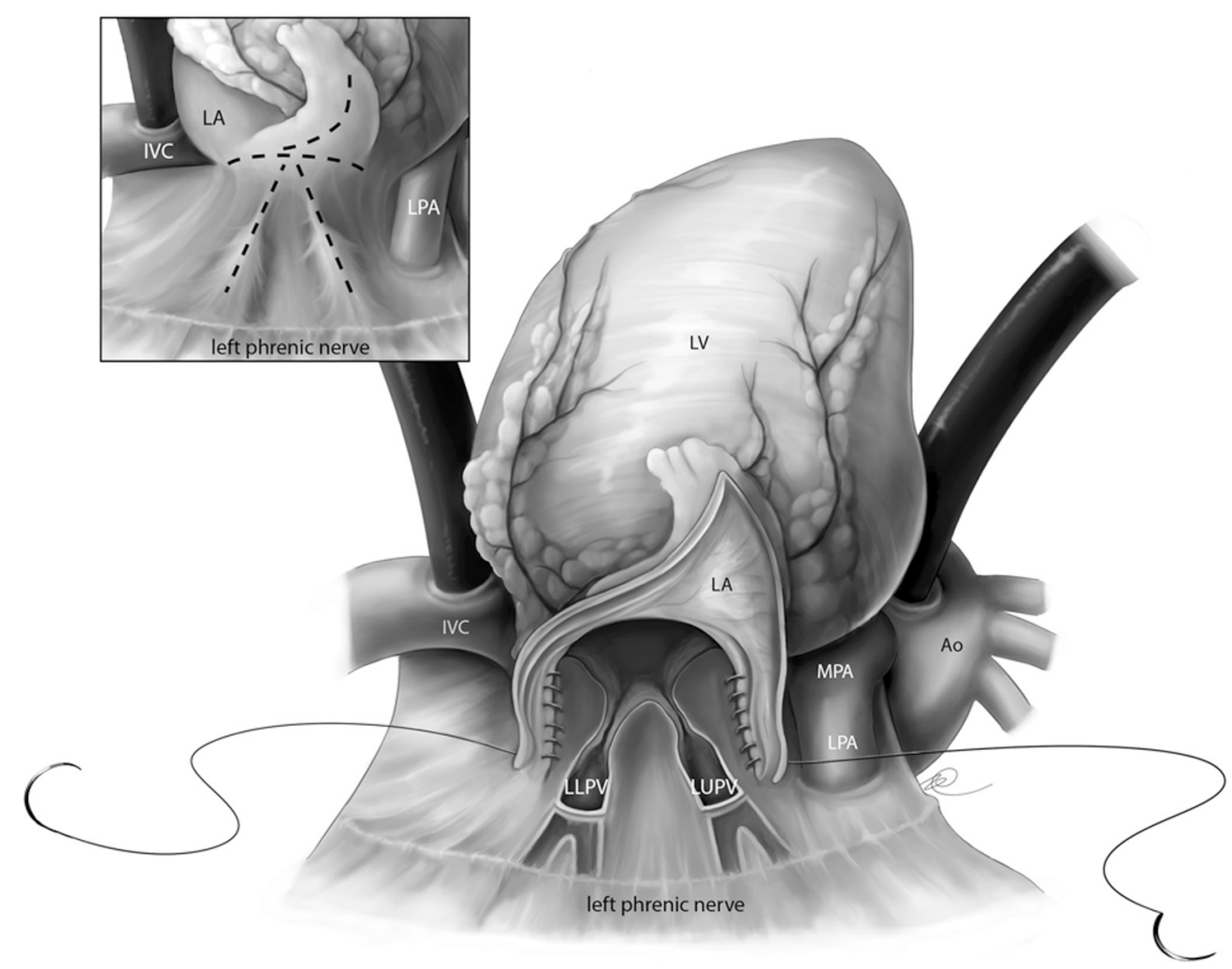

FIGURE 3. Sutureless repair of left-sided pulmonary vein stenosis (PVS). The sutureless repair involves aggressive resection of stenotic pulmonary veins with subsequent suturing of the left atrium directly to the pericardium, thereby minimizing intimal injury of the pulmonary veins associated with suturing and avoids any anatomical distortion at the venoatrial junction caused by the sutureline. $L A$, Left atrium; IVC, inferior vena cava; $L P A$, left pulmonary artery; $L V$, left ventricle; $M P A$, main pulmonary artery; $A o$, aorta; $L L P V$, left lower pulmonary vein; $L U P V$, left upper pulmonary vein. Reprint permission granted by Rachel Vanderlaan, PVSNetwork.org.

the pericardial reflection, with reconstruction of the hood of the venoatrial junction typically with homograft material. ${ }^{38}$ The approach attempts to maximize laminar flow patterns and contrasts the sutureless approach with direct suturing of the pulmonary veins. Other potential surgical adjuncts include stent deployment at the time of surgical
Survival (1-year) stratified by Upstream TCSAi vs Downstream TCSAi

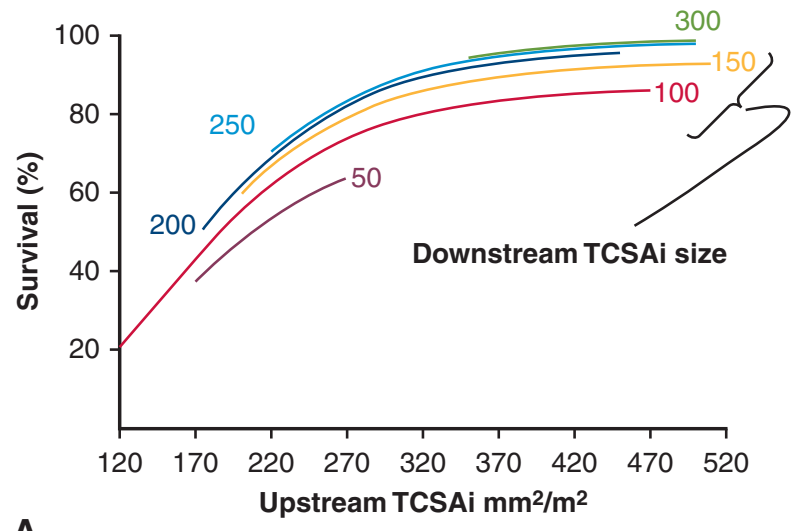

A

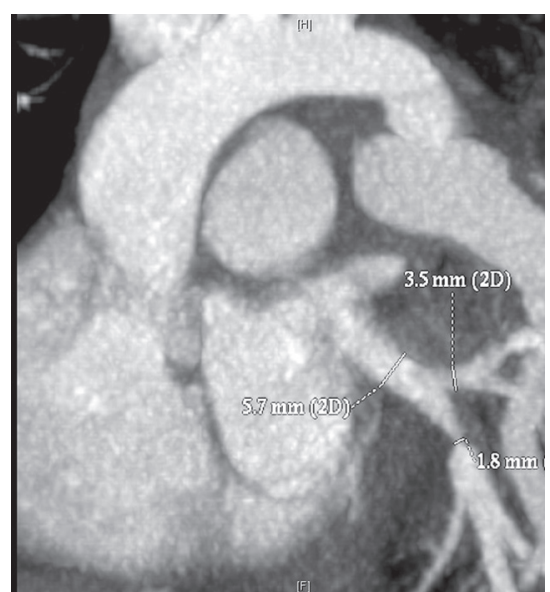

B

FIGURE 4. Imaging of the pulmonary veins. A, Modeling data demonstrating the influence of smaller cross-sectional area of upstream pulmonary veins compared with downstream cross-sectional area. With decreased upstream total indexed cross sectional area (TCSAi) survival decreases. Changes in downstream TCSAi have less influence on survival. Reproduced with permission from Lo Rito and colleagues. ${ }^{35}$ B, Computed tomography angiography measurements at different locations. Image courtesy of Dr Yoo, Hospital for Sick Children. 
intervention ${ }^{39}$ and the potential use of experimental drugeluting films in the future. ${ }^{40}$

\section{Adjuvant and Experimental Therapies}

Emerging experimental therapies have the potential to slow the progression of PVS. Adjuvant therapies such as pulmonary arterial antihypertension medications (eg, sildenafil and bosentan) are often prescribed off label to improve right ventricular function; however, their use is somewhat controversial due to concerns of worsening pulmonary edema noted in patients with pulmonary venoocclusive disease. ${ }^{41}$ Registry data from the PVS Network will be important to evaluate current utilization patterns in PVS management.

Experimental therapies for PVS have been evaluated in single-armed clinical trials and retrospective studies. Two clinical trials targeted myofibroblast hypercellularity using chemotherapeutic agents, with the rationale based on histological characteristics of end-stage human PVS samples. A pilot phase II trial evaluated the safety and efficacy of methotrexate and vinblastine (NCT00215046) in children with advanced primary PVS, demonstrating a 1-year survival of $38 \%$ with a high incidence of clinically significant side effects. ${ }^{42}$ A second single-arm trial (NCT00891527) targeted PVS using imatinib, a tyrosine kinase inhibitor, and bevacizumab, an angiogenesis blocker that inhibits vascular endothelial growth factor (developed as a cancer chemotherapy agent), reporting 72 -week survival of $77 \%$, an improvement over the results of methotrexate and vinblastine. ${ }^{43}$ A retrospective study compared a contemporary surgical/interventional cohort with those who additionally received imatinib and bevacizumab demonstrated no difference in overall mortality between the groups ${ }^{3}$; however, propensity matching was not employed. The third singlearm pilot trial is based on a porcine model of progressive PVS where losartan administration reduced neointimal formation potentially through inhibition of transforming growth factor beta-mediated endothelial to mesenchymal transition $^{20}$; the results of the trial (NCT02769130) are anticipated in 2021. In addition, a recent retrospective study reported an institutional experience of systemic rapamycin for treatment of ISS primarily in patients receiving BMS and demonstrated reduced rates of ISS compared with pretreatment rates of stenosis. ${ }^{33}$

Mechanical pulmonary support. Conventional mechanical support for children with end-stage right ventricular failure is veno-arterial extracorporeal membrane oxygenation. There is potential to apply alternative mechanical support strategies for adult patients with end-stage pulmonary hypertension to patients with PVS.

Use of passive (pumpless) high-efficiency oxygenators in a pulmonary artery-left atrium arrangement have enabled oxygenation support and right ventricular decompression in patients with refractory pulmonary hypertension as a strategy for pretransplant palliation in adult lung transplantation. ${ }^{44}$ Although not reported in pediatric patients with PVS, Quadrox-iD (Maquet Cardiopulmonary AG, Hirrlingen, Germany) devices have been described in neonates and children with refractory pulmonary hypertension. ${ }^{45,46}$ Alternatively, adult patients with pulmonary hypertension can be bridged using a dual lumen internal jugular cannula in a venovenous extracorporeal membrane oxygenation configuration (Avalon; Maquet Cardiopulmonary AG), ${ }^{47}$ with inflow from the inferior cavoatrial junction and outflow directed toward an atrial septal defect (created in the catheterization lab when necessary). Although not reported in infants with PVS, conceptually this may decompress the right ventricle in the setting of PVS. Important considerations would be appropriate creation of an atrial septal defect for cannula alignment, risk of perforation and recirculation.

Lung transplantation. Pediatric lung transplantation has an overall median survival of 5.4 years and is an option for children with refractory PVS. ${ }^{48}$ Heart-lung transplantation may be appropriate in select PVS patients with concomitant congenital heart disease. Waitlist mortality can be high in infants due to reduced allocation of pediatric lungs and the lack of long-term mechanical pulmonary support options in children with weight $<15 \mathrm{~kg} .{ }^{49,50}$ Use of ex vivo lung perfusion may be a mechanism to evaluate lungs and increase use of donor pediatric lungs. ${ }^{51} \mathrm{~A}$ single-center report of pediatric lung transplant outcomes in 20 children with PVS described overall 5-year survival of $67.3 \%$ for primary PVS and $50.7 \%$ for PR-PVS, ${ }^{52}$ suggesting this is a feasible treatment for end-stage disease.

\section{CURRENT CHALLENGES}

\section{Refractory Disease: A Need to Understand the Molecular Drivers of PVS}

Refractory disease is relentless and presents unique challenges and limitations with respect to surgical reoperation and catheter reinterventions. Reconstruction of a sutureless anastomosis in a redo situation can be challenging, with increased risk of phrenic nerve injury and the potential need for patch material to reconstruct the venoatrial hood, if restenosis occurs outside the pericardial reflection. Scarring and disease progression into the interparenchymal pulmonary veins can limit the feasibility of repair. In addition, transcatheter pulmonary vein interventions have their own set of challenges in the setting of recurrent disease. Treatment of ISS in addition to recurrent PVS can necessitate multiple reinterventions with the risk of thrombosis of common access vessels. Alternative access can include transhepatic and transthoracic access or deployment of a stent at the time of surgical intervention; however, such access strategies significantly increase risk decreasing the feasibility 
of multiple reinterventions. A focus on basic science investigations to elucidate the molecular drivers of PVS may lead to additional experimental therapeutic agents that slow the progression of PVS and ISS. Animal surgical models of PVS are actively being used to understand neointimal formation, ${ }^{19,43}$ and ongoing PVS Network whole genome sequencing and biomarker projects will potentially provide unique insights into the pathophysiology of PVS.

\section{Treatment of Atretic Pulmonary Veins}

Due to silent clinical progression of PVS, surveillance is required to identify early recurrence and allow for timely interventions. Following TAPVC repair or with advanced primary disease, atretic pulmonary veins can come to attention due to hemoptysis episodes, recurrent infections or as an incidental finding on imaging. Surgical revision requires adequately sized upstream veins to allow for aggressive resection, whereas successful transcatheter recanalization of atretic pulmonary veins in a large cohort of pediatric patients with minimal complications has been reported. ${ }^{53}$ Although the long term success is still unknown, the technical advancement will provide a foundation to address atretic pulmonary veins.

\section{CLINICAL CONSENSUS WITHIN INSTITUTIONS AND ACROSS INSTITUTIONS \\ Institutional PVS Teams and Clinical Surveillance Protocols}

As a result of the relative rarity of disease and clinical heterogeneity, children with PVS are often dispersed among multiple clinicians at a single institution. Adoption of a PVS team-based approach consisting of cardiologists, surgeons, interventionalists, neonatologists, imaging specialists, lung transplant physicians, and representatives from other specialities can accelerate learning and concentrate expert decision making, while providing more consistent surveillance for recurrent disease (Figure 5).

Adoption of a clinical surveillance protocol provides a consistent framework for detection of disease progression through the use of echocardiography, complementary imaging modalities, and team decision making. A clinical surveillance protocol ideally adopts a proactive management framework for clinical care, with each subsequent treatment intervention requiring surveillance and re-evaluation of treatment options. Engagement of a team-based approach that seeks to treat early progression maximizes opportunities for timely intervention. This approach can lead to

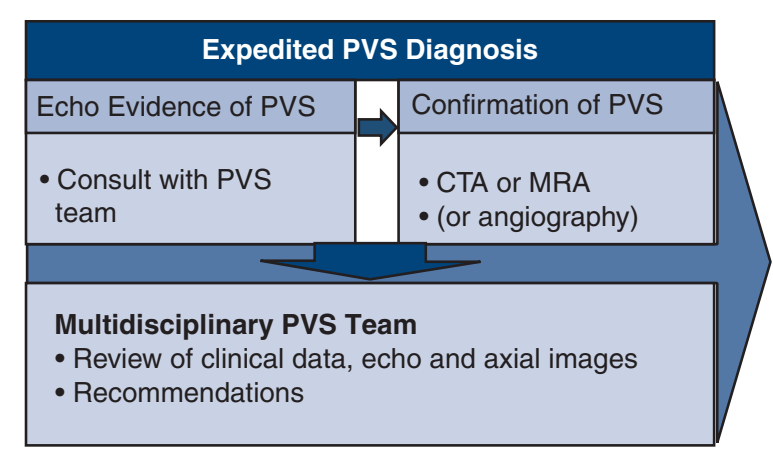
team consists of surgeon, interventional cardiologists, ward cardiologists, imaging and echocardiography cardiologists, members of the lung transplant team, and others. They meet regularly to review the condition of inpatients and surveillance imaging of outpatients and make recommendations toward management strategies. When a new PVS patient is identified, adjunct imaging is obtained to understand the anatomy, confirm the diagnosis, and inform treatment plans. Initial discussions should include consideration for candidacy for experimental medications if the child has risk factors for progressive disease. Using a teambased approach, surgical or catheter interventions are preformed in a timely manner. Integral to this proactive management cycle is ensuring timely surveillance following any major intervention to detect early restenosis. Additional follow-up is designed to ensure early detection and is in line with recommendations for subsequent interventions. In children with severe disease who are in an aggressive proactive phase of management, this can result in a monthly reassessment of the veins by echocardiography and other adjunct modalities. Parent and team discussions are required to design dynamic treatment plans that work toward the desired outcome (eg, disease stabilization, transplantation, or palliation). CTA, Computed tomography angiography. 
complex management pathways, yet it seeks to integrate available tools to best fit the patient and move him or her toward the desired goal of disease stabilization or transplant.

\section{Multi-institutional Collaboration}

Multi-institutional collaboration is required to optimally advance care for PVS patients. The recently formed of the PVS Network (www.PVSNetwork.org) currently has 18 institutions participating across North America, with a PVS Network retrospective registry cohort composed of more than 600 patients. This cohort will serve to define current practice patterns and outcomes but also power ongoing prospective PVS Network registry studies, and allow for propensity matching. Ultimately, the PVS Network should enable and inform the development of evidence-based consensus guidelines for the management of PVS.

\section{CONCLUSIONS}

Clinical care for children with PVS has the potential to advance rapidly, with integration of surgical techniques, catheter-based strategies, and experimental therapies. Most importantly, basic science investigations and multiinstitutional studies will help accelerate knowledge generation and improve patient outcomes.

\section{Conflict of Interest Statement}

The University of Colorado contracts with Actelion, Bayer, Glaxo, Lilly, and United Therapeutics for Dr Ivy to be a consultant. All other authors reported no conflicts of interest.

The Journal policy requires editors and reviewers to disclose conflicts of interest and to decline handling or reviewing manuscripts for which they may have a conflict of interest. The editors and reviewers of this article have no conflicts of interest.

The authors thank Ruth Chang for contributing to the medical illustrations.

\section{References}

1. Latson LA, Prieto LR. Congenital and acquired pulmonary vein stenosis. Circulation. 2007;115:103-8.

2. Seale AN, Webber SA, Uemura H, Partridge J, Roughton M, Ho SY, et al. Pulmonary vein stenosis: the UK, Ireland and Sweden collaborative study. Heart. 2009;95:1944-9.

3. Quinonez LG, Gauvreau K, Borisuk M, Ireland C, Marshall AM, Mayer JE, et al. Outcomes of surgery for young children with multivessel pulmonary vein stenosis. J Thorac Cardiovasc Surg. 2015;150:911-7.

4. Viola N, Alghamdi AA, Perrin DG, Wilson GJ, Coles JG, Caldarone CA. Primary pulmonary vein stenosis: the impact of sutureless repair on survival. J Thorac Cardiovasc Surg. 2011;142:344-50.

5. Kalfa D, Belli E, Bacha E, Lambert V, di Carlo D, Kostolny M, et al. Primary pulmonary vein stenosis: outcomes, risk factors, and severity score in a multicentric study. Ann Thorac Surg. 2017;104:182-9.

6. Drossner DM, Kim DW, Maher KO, Mahle WT. Pulmonary vein stenosis: prematurity and associated conditions. Pediatrics. 2008;122:e656-61.

7. Mahgoub L, Kaddoura T, Kameny AR, Lopez Ortego P, Vanderlaan RD, Kakadekar A, et al. Pulmonary vein stenosis of ex-premature infants with pulmonary hypertension and bronchopulmonary dysplasia, epidemiology, and survival from a multicenter cohort. Pediatr Pulmonol. 2017;52:1063-70.

8. Swier NL, Richards B, Cua CL, Lynch SK, Yin H, Nelin LD, et al. Pulmonary vein stenosis in neonates with severe bronchopulmonary dysplasia. Am J Perinatol. 2016;33:671-7.

9. Seale AN, Uemura H, Webber SA, Partridge J, Roughton M, Ho SY, et al. Total anomalous pulmonary venous connection: outcome of postoperative pulmonary venous obstruction. J Thorac Cardiovasc Surg. 2013;145:1255-62.

10. Shi G, Zhu Z, Chen J, Ou Y, Hong H, Nie Z, et al. Total anomalous pulmonary venous connection: the current management strategies in a pediatric cohort of 768 patients. Circulation. 2017;135:48-58.

11. Kalfa D, Belli E, Bacha E, Lambert V, di Carlo D, Kostolny M, et al. Outcomes and prognostic factors for postsurgical pulmonary vein stenosis in the current era. J Thorac Cardiovasc Surg. 2018;156:278-86.

12. van de Laar I, Wessels M, Frohn-Mulder I, Dalinghaus M, de Graaf B, van Tienhoven M, et al. First locus for primary pulmonary vein stenosis maps to chromosome 2q. Eur Heart J. 2009;30:2485-92.

13. Somi S, Buffing AAM, Moorman AFM, Van Den Hoff MJB. Dynamic patterns of expression of BMP isoforms 2, 4, 5, 6, and 7 during chicken heart development Anat Rec A Discov Mol Cell Evol Biol. 2004;279:636-51.

14. Gao Y, Raj JU. Role of veins in regulation of pulmonary circulation. Am J Physiol Lung Cell Mol Physiol. 2005;288:L213-26.

15. Kotani Y, Zhu J, Grosse-Wortmann L, Honjo O, Coles JG, Van Arsdell GS, et al Anatomical risk factors, surgical treatment, and clinical outcomes of left-sided pulmonary vein obstruction in single-ventricle patients. J Thorac Cardiovasc Surg. 2015;149:1332-8.

16. Sadr IM, Tan PE, Kieran MW, Jenkins KJ. Mechanism of pulmonary vein stenosis in infants with normally connected veins. Am J Cardiol. 2000;86:577-9. A10.

17. Kovach AE, Magcalas PM, Ireland C, McEnany K, Oliveira AM, Kieran MW et al. Paucicellular fibrointimal proliferation characterizes pediatric pulmonary vein stenosis: clinicopathologic analysis of 213 samples from 97 patients. Am J Surg Pathol. 2017;41:1198-204.

18. Riedlinger WFJ, Juraszek AL, Jenkins KJ, Nugent AW, Balasubramanian S, Calicchio ML, et al. Pulmonary vein stenosis: expression of receptor tyrosine kinases by lesional cells. Cardiovasc Pathol. 2006;15:91-9.

19. Kato H, Fu YY, Zhu J, Wang L, Aafaqi S, Rahkonen O, et al. Pulmonary vein stenosis and the pathophysiology of "upstream" pulmonary veins. J Thorac Cardiovasc Surg. 2014;148:245-53.

20. Zhu J, Ide H, Fu YY, Teichert A-M, Kato H, Weisel RD, et al. Losartan ameliorates "upstream" pulmonary vein vasculopathy in a piglet model of pulmonary vein stenosis. J Thorac Cardiovasc Surg. 2014;148:2550-7.

21. Roman KS, Kellenberger CJ, Macgowan CK, Coles J, Redington AN, Benson LN, et al. How is pulmonary arterial blood flow affected by pulmonary venous obstruction in children? A phase-contrast magnetic resonance study Pediatr Radiol. 2005;35:580-6.

22. Hirsch R, Gottliebson W, Crotty E, Fleck R, Strife J. Computed tomography angiography with three-dimensional reconstruction for pulmony venous definition in high-risk infants with congenital heart disease. Congenit Heart Dis. 2006;1: 104-10.

23. Barrera CA, Saul D, Rapp JB, Smith CL, White AM, Biko DM, et al. Diagnostic performance of CT angiography to detect pulmonary vein stenosis in children. Int J Cardiovasc Imaging. 2020;36:141-7.

24. Greenway SC, Yoo S-J, Baliulis G, Caldarone C, Coles J, Grosse-Wortmann L. Assessment of pulmonary veins after atrio-pericardial anastomosis by cardiovascular magnetic resonance. J Cardiovasc Magn Reson. 2011;13:72.

25. Grosse-Wortmann L, Al-Otay A, Goo HW, Macgowan CK, Coles JG Benson LN, et al. Anatomical and functional evaluation of pulmonary veins in children by magnetic resonance imaging. J Am Coll Cardiol. 2007;49:993-1002.

26. Drubach LA, Jenkins KJ, Stamoulis C, Palmer EL III, Lee EY. Evaluation of primary pulmonary vein stenosis in children: comparison of radionuclide perfusion lung scan and angiography. AJR Am J Roentgenol. 2015;205:873-7.

27. Peng LF, Lock JE, Nugent AW, Jenkins KJ, McElhinney DB. Comparison of conventional and cutting balloon angioplasty for congenital and postoperative pulmonary vein stenosis in infants and young children. Catheter Cardiovasc Interv. 2010;75:1084-90.

28. Balasubramanian S, Marshall AC, Gauvreau K, Peng LF, Nugent AW, Lock JE et al. Outcomes after stent implantation for the treatment of congenital and postoperative pulmonary vein stenosis in children. Circ Cardiovasc Interv. 2012;5: 109-17.

29. Muller MJ, Krause U, Paul T, Schneider HE. Serum levels after everolimus-stent implantation and paclitaxel-balloon angioplasty in an infant with recurrent 
pulmonary vein obstruction after repaired total anomalous pulmonary venous connection. Pediatr Cardiol. 2011;32:1036-9.

30. Khan A, Qureshi AM, Justino H. Comparison of drug eluting versus bare metal stents for pulmonary vein stenosis in childhood. Catheter Cardiovasc Interv. 2019;94:233-42.

31. Cory MJ, Ooi YK, Kelleman MS, Vincent RN, Kim DW, Petit CJ. Reintervention is associated with improved survival in pediatric patients with pulmonary vein stenosis. JACC Cardiovasc Interv. 2017;10:1788-98.

32. Agrawal H, Qureshi AM, Justino H. Intentional longitudinal and side-cell stent fractures: intermediate term follow-up. Catheter Cardiovasc Interv. 2018;91: 1110-8.

33. Callahan R, Esch JJ, Wang G, Ireland CM, Gauvreau K, Jenkins KJ. Systemic sirolimus to prevent in-stent stenosis in pediatric pulmonary vein stenosis. Pediatr Cardiol. 2020;41:282-9.

34. Honjo O, Atlin CR, Hamilton BCS, Al-Radi O, Viola N, Coles JG, et al. Primary sutureless repair for infants with mixed total anomalous pulmonary venous drainage. Ann Thorac Surg. 2010;90:862-8.

35. Lo Rito M, Gazzaz T, Wilder TJ, Vanderlaan RD, Van Arsdell GS, Honjo O, et al. Pulmonary vein stenosis: severity and location predict survival after surgical repair. J Thorac Cardiovasc Surg. 2016;151:657-66.e2.

36. Lacour-Gayet F, Rey C, Planche C. Pulmonary vein stenosis. Description of a sutureless surgical procedure using the pericardium in situ [article in French]. Arch Mal Coeur Vaiss. 1996;89:633-6.

37. Najm HK, Caldarone CA, Smallhorn J, Coles JG. A sutureless technique for the relief of pulmonary vein stenosis with the use of in situ pericardium. $J$ Thorac Cardiovasc Surg. 1998;115:468-70.

38. Feins EN. Surgical video: Repair of primary pulmonary vein stenosis (premie). Available at: https://www.aats.org/aatsimis/AATSWeb/Association/Meetings/ Annual_Meeting/99th_Annual_Meeting/AATS_99th_Annual_Meeting_Sessions/ PULMONARY_VEIN_SURGERY.aspx. Accessed July 5, 2020.

39. Yoon JK, Kim GB, Song MK, Bae EJ, Kim WH, Kwak JG, et al. Hybrid pulmonary vein stenting in infants with refractory to surgical pulmonary vein stenosis repair. Pediatr Cardiol. 2018;39:1642-9.

40. Masaki N, Adachi O, Katahira S, Saiki Y, Horii A, Kawamoto S. Progression of vascular remodeling in pulmonary vein obstruction. J Thorac Cardiovasc Surg. February 26, 2020 [Epub ahead of print].

41. Sourla E, Paspala A, Boutou A, Kontou P, Stanopoulos I, Pitsiou G. A case of pulmonary veno-occlusive disease: diagnostic dilemmas and therapeutic challenges. Ther Adv Respir Dis. 2013;7:119-23.

42. Rehman M, Jenkins KJ, Juraszek AL, Connor JA, Gauvreau K, Muneeb M, et al. A prospective phase II trial of vinblastine and methotrexate in multivessel intraluminal pulmonary vein stenosis in infants and children. Congenit Heart Dis. 2011;6:608-23.
43. Callahan R, Kieran MW, Baird CW, Colan SD, Gauvreau K, Ireland CM, et al. Adjunct targeted biologic inhibition agents to treat aggressive multivessel intraluminal pediatric pulmonary vein stenosis. J Pediatr. 2018;198:29-35.e5.

44. Hoetzenecker K, Donahoe L, Yeung JC, Azad S, Fan E, Ferguson ND, et al. Extracorporeal life support as a bridge to lung transplantation-experience of a high-volume transplant center. J Thorac Cardiovasc Surg. 2018;155: 1316-13128.e1.

45. Hoganson DM, Gazit AZ, Boston US, Sweet SC, Grady RM, Huddleston CB, et al. Paracorporeal lung assist devices as a bridge to recovery or lung transplantation in neonates and young children. J Thorac Cardiovasc Surg. 2014;147: 420-6.

46. Gazit AZ, Sweet SC, Grady RM, Boston US, Huddleston CB, Hoganson DM, et al. Recommendations for utilization of the paracorporeal lung assist device in neonates and young children with pulmonary hypertension. Pediatr Transplant. 2016;20:256-70.

47. Javidfar J, Brodie D, Sonett J, Bacchetta M. Venovenous extracorporeal membrane oxygenation using a single cannula in patients with pulmonary hypertension and atrial septal defects. J Thorac Cardiovasc Surg. 2012;143: 982-4.

48. Goldfarb SB, Levvey BJ, Cherikh WS, Chambers DC, Khush K, Kucheryavaya AY, et al. Registry of the International Society for Heart and Lung Transplantation: twentieth pediatric lung and heart-lung transplantation report-2017; focus theme: allograft ischemic time. J Heart Lung Transplant. 2017;36:1070-9.

49. Lancaster TS, Miller JR, Epstein DJ, DuPont NC, Sweet SC, Eghtesady P. Improved waitlist and transplant outcomes for pediatric lung transplantation after implementation of the lung allocation score. J Heart Lung Transplant. 2017;36: $520-8$.

50. Sweet SC, Barr ML. Pediatric lung allocation: the rest of the story. Am J Transplant. 2014;14:11-2.

51. Galasso M, Vanderlaan RD, Solomon M, Caldarone C, Keshavjee S, Cypel M, et al. A successful lung transplant from a 3-year-old donor after controlled cardiac death followed by ex vivo lung perfusion: a case report. J Thorac Cardiovasc Surg. 2019;158:e149-52.

52. Bharat A, Epstein DJ, Grady M, Faro A, Michelson P, Sweet SC, et al. Lung transplant is a viable treatment option for patients with congenital and acquired pulmonary vein stenosis. J Heart Lung Transplant. 2013;32:621-5.

53. Varun A, Stapleton GE, Henri J. Abstract 15827: pulmonary vein atresia: transcatheter interventions and long-term outcomes. Circulation. 2019;140(Suppl 1): A15827.

Key Words: pulmonary vein stenosis, pediatrics, right heart failure 